\title{
How conspiracists exploited COVID-19 science
}

\author{
During the COVID-19 pandemic, conspiracy theorists have exploited the provisional nature of scientific consensus \\ and the realities of how science is conducted to paint scientists and public health leaders as malign actors.
}

\author{
Kathleen Hall Jamieson
}

\begin{abstract}
nstead of envisioning an untidy world
filled with randomness, unintended

consequences, innocent action gone awry and new evidence, conspiracists envision one that is inhabited by powerful individuals who conceal malign activities and intent. The fluid nature of emergent science provides fuel for conspiracy theorists who offer certainty in place of the provisional, sometimes-updated statements of health experts. At the same time, conspiracy proponents question the trustworthiness and motives of those in the federal agencies, philanthropic institutions and pharmaceutical companies who fund basic research and develop, deliver and, in the case of some of the federal agencies, regulate public access to medical treatments, including vaccines.

Filtering the world through these lenses, during the pandemic conspiracists have drawn on and manipulated statements and actions by public health experts, such as Dr Anthony Fauci (director of the US National Institute of Allergy and Infectious Diseases), on topics that range from mask wearing and COVID-19 treatments to vaccine safety and the funding of coronavirus research. Understanding the susceptibilities that conspiracists exploit should help us to identify ways to better safeguard both the trustworthiness of health science and public trust in it.
\end{abstract}

\section{The updating of scientific knowledge}

Statements and updates by Dr Fauci about mask wearing and hydroxychloroquine were among those used by conspiracy theorists during the pandemic. As indications accumulated that individuals without symptoms can transmit SARS-CoV-2, the Centers for Disease Control and Prevention (CDC), the Surgeon General and Dr Fauci did an about-face on the advisability of routine mask wearing in public settings. When randomized, placebo-controlled clinical trials found that hydroxychloroquine was ineffective as a COVID-19 treatment, Dr Fauci's agnosticism about its value shifted to opposition. He was not alone. The US Food and Drug Administration (FDA) also withdrew its Emergency Use Authorization of it. "Much of what Fauci said about this virus, the drugs that could treat it, and the measures that could be taken to slow the spread was untrue", said Fox News's Laura Ingraham on the 2 June 2021, "He knew it was untrue". After listing "cruise ships, masks, lockdowns, the origins of COVID19 , [and] the models and projections" as topics on which Dr Fauci had been "wrong", on 2 June 2021, Fox News's Sean Hannity asked "What did Dr Fauci know and [w] hen did Dr Fauci know it, and was he engaged in some kind of scientific cover-up?".

For conspiracists of an ideologically conservative bent, some of conclusions of the science community did not reflect science but instead a desire to undercut Trump's re-election prospects. "The partisan Democrats, the conjugal media, and the scientists, the deep state scientists want America sick through November", alleged Michael Caputo, who was appointed by Trump as assistant health and human services secretary for public affairs. Among the decisions at issue were whether the whole population other than essential workers needed to be 'locked down' to 'bend the curve', the speed with which the economy should be re-opened after the 'lockdown' and when a vaccine would be available for distribution. The insistence of experts such as Dr Fauci that decisions about the use of proposed treatments such as hydroxychloroquine and convalescent plasma, and the authorization of a COVID19 vaccine, should await high-quality clinical trial data was also interpreted as being anti-Trump in intent. "The deep state, or whoever, over at the FDA is making it very difficult for drug companies to get people in order to test the vaccines and therapeutics. Obviously, they are hoping to delay the answer until after November 3rd", tweeted President Trump on 22 August 2020.

\section{Funding structures in science}

A desire to sabotage the electoral prospects of the incumbent US president was not the only motive that conspiracists saw at work. Greed and abuse of power and trust were assumed to be at play as well. Presuppositions of self-interested collusion among actors in federal agencies, philanthropic institutions and the biopharmaceutical industry incorporate two accurate premises: they are all major funders of health science, and the pharmaceutical companies commercialize federally funded research. But what is actually going on, according to Robert F. Kennedy Jr, the head of the anti-vaccination organization Children's Health Defence, is more sinister: philanthropist Bill Gates pays Dr Fauci, who in turn develops drugs and passes them to drug companies in which Gates is invested. Gates then guarantees markets in Africa through his control of the World Health Organization (WHO), which requires those countries to buy the drugs and vaccines ${ }^{1}$.

The process of generating conspiracy theories interweaves uncontested facts about ongoing activities in the government, philanthropic institutions and biopharmaceutical companies (for example, that the Gates Foundation funds vaccine development or that post-vaccination deaths have been reported to the US government's Vaccine Adverse Event Reporting System); historical instances in which a pattern of allegedly comparable behaviour occurred (for example, that the US government authorized the 1932-1972 syphilis experiments at Tuskegee or that babies of colour were given an unlicensed vaccine in the early 1990s without their parents' informed consent ${ }^{2}$ ); and pre-existing unwarranted conspiracy theories (for example, that the CDC is covering up evidence that the measles, mumps and rubella (MMR) vaccine causes autism). A conspiracy theory may also convert temporal associations into causal inferences (as in a since-deleted Instagram post $^{3}$ claiming that Hank Aaron and Marvelous Marvin Hagler "died after taking the COVID-19 vaccine." The COVID vaccine killed both!). "Coincidence is turning out to be quite lethal to COVID vaccine recipients", noted Kennedy ${ }^{4}$.

Into this brew, conspiracists add conjecture ("maybe [the COVID-19 vaccine] doesn't work and they're simply not telling you that" ${ }^{\text {) }}$ ) and insinuations that are intended to identify a conspirator's motive (for example, that Dr Fauci is a registered Democrat $^{6}$, a past CEO of Moderna ${ }^{7}$ and a vaccine shareholder $\left.{ }^{8}\right)$. Such factors are interlaced to warrant context-specific 
conspiracy theories (for example, that the FDA is covering up the fact that the mRNA vaccines cause serious side effects and death'; or that, in league with 'Big Pharma', Dr Fauci mandates vaccines from which he, Big Pharma, the Gates Foundation, Chan-Zuckerberg, WHO, CDC and the Chinese Communist Party benefit ${ }^{10}$ ).

Personal greed is one ascribed motive, and sociopathy or lust for power, glory and knowledge are others. Accordingly, one theory accuses Dr Fauci of opposing the approval of hydroxychloroquine - a drug that Trump cast as a possible "game changer" 11 - because Dr Fauci wanted the virus to spread until a vaccine could be developed and named after him ${ }^{12}$. On another front, by terming the nation's leading infectious disease specialist the 'father of the virus', conspiracists assumed the motive explored in Mary Shelley's Frankenstein - an arrogant search for knowledge unmindful of the risks or consequences. The meme 'Fauci Lied. Millions Died'13 capsulizes the conspiracy assertion that by denying that a US $\$ 600,000$ National Institutes of Health (NIH) subaward from EcoHealth Alliance to the Wuhan Institute of Virology ${ }^{14}$ involved gain-of-function research, Dr Fauci and compatriots such as NIH director Dr Francis Collins are covering up (that is, 'Fauci Lied') the supposed reality that the resulting explorations created SARS-CoV-2 and with it the pandemic (that is, 'Millions Died').

Here, conspiracists are exploiting uncertainty about the genesis of SARS-CoV-2. As the presidents of the National Academies of Sciences, Engineering and Medicine noted in a statement on 15 June 2021, "The origin of SARS-CoV-2, the virus that causes COVID19 , and the circumstances of the first cases of human infection, remain unknown". Whether intended as parody or not, former Daily Show host Jon Stewart reinforced the broader inference when, appearing on The Late Show with Stephen Colbert on 14 June 2021, he told the host Stephen Colbert, "I think we owe a great debt of gratitude to science. Science has, in many ways, helped ease the suffering of this pandemic - which was more than likely caused by science".

\section{Proactively reducing susceptibility}

Because those with a conspiratorial world view can readily cast their critics as part of the conspiracy ${ }^{15}$ and massage evidence that contravenes a particular theory into proof of $\mathrm{it}^{16}$, they are unlikely to be persuaded by counterevidence ${ }^{17}$. However, as David Robert Grimes has suggested, acceptance of "medico-scientific consensus" is a spectrum that includes those who are reachable ${ }^{18}$. Our goal should be reaching them.

To minimize conspiracists' exploitation of instances in which scientific authorities update scientific knowledge, health experts ought to note routinely that their statements are based on 'what we now know'. When, as in the case of mask wearing, fresh evidence prompts an apparent U-turn, public health spokespersons should justify the change by repeatedly explaining 'what we know now that we didn't know then'.

Scientists and journalists also should showcase the ways in which the scientific norms of transparency and critique both forestall and make it possible to uncover the effects of human bias and venality on the research enterprise. Federal grants are not only subject to extensive review by multiple parties, but also - as press review of the EcoHealth Alliance's NIH award attests - their provisions are subject to public scrutiny. Moreover, it was institutionalized forms of disclosure (for example, the US Securities and Exchange Commission's database) that made it possible for fact checkers to confirm that Dr Fauci is not a vaccine shareholder. Fact checkers used other open sources to undercut claims that he is a registered Democrat or a past CEO of Moderna. And publications were retracted that "relied on a significant amount of data" from what Retraction Watch characterized as "a questionable company.... which is now famous for refusing to share its data in articles published in The Lancet and The New England Journal of Medicine" ${ }^{19}$.

By exploiting the provisional nature of scientific knowledge, its inevitable updating and the realities of the scientific funding structures, conspiracists eroded the trust of some susceptible individuals in the recommendations of public health authorities about lifesaving behaviours including mask wearing and vaccination. Their success in doing so made community immunity, and with it an end to the pandemic, more elusive. Understanding the vulnerabilities that conspiracists exploit should help us to identify ways to better safeguard both the trustworthiness of health science and public trust in it.

Kathleen Hall Jamieson (D) $ه$ Annenberg Public Policy Center, University of Pennsylvania, Philadelphia, PA, USA.

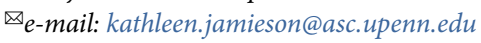

Published online: 1 November 2021

https://doi.org/10.1038/s41562-021-01217-2

References

1. Mercola, J. [@mercola]. Major conspiracy [tweet]. Twitter, https://mobile.twitter.com/mercola/status/1384214816907087872 (19 April 2021).

2. Cimons, M. U.S. Measles Experiment Failed to Disclose Risk. The Washington Post, https://www.washingtonpost.com/archive/ politics/1996/06/17/us-measles-experiment-failed-to-disclose-ris k/6a4dd6ce-7add-4daa-8c5e-6e5fc343b996/ (17 June 1996).

3. Kertscher, T. Claim blaming COVID vaccine for Hank Aaron, Marvin Hagler deaths lacks evidence. Politifact, https://www.politifact.com/factchecks/2021/mar/16/aubreyhuff/claim-blaming-covid-vaccine-hank-aaron-marvin-hagl/ (16 March 2021).

4. Kennedy, R. F. Death by coincidence? The Defender, https://childrenshealthdefense.org/defender/death-bycoincidence/ (14 January 2021).

5. Tucker Carlson Tonight. J\&J vaccine paused over blood clot concerns. Facebook, https://www.facebook.com/Tucker CarlsonTonight/videos/1145773552514245/ (13 April 2021).

6. Colson, T. Trump says 'everyone knows' that Dr. Fauci is a Democrat, despite the fact that he is not a member of any party. Insider, https://www.businessinsider.com/donald-trump-claimsdr-fauci-is-a-democrat-no-evidence-2020-10 (16 October 2020).

7. Reuters Staff. Fact check: Dr. Fauci was not the first CEO and other false claims about biotech company Moderna. Reuters, https://www.reuters.com/article/uk-factcheck-moderna-faucigates/fact-check-dr-fauci-was-not-the-first-ceo-and-other-falseclaims-about-biotech-company-moderna-idUSKBN25S5GD (1 September 2020).

8. Funke, D. Facebook posts falsely claim Dr. Fauci has millions invested in a coronavirus vaccine. PolitiFact, https://www. politifact.com/factchecks/2020/apr/15/facebook-posts/facebookposts-falsely-claim-dr-fauci-has-millions/ (15 April 2020)

9. Fichera, A. Instagram post misrepresents FDA document about monitoring vaccine safety. FactCheck.org, https://www. factcheck.org/2021/03/scicheck-instagram-post-misrepresentsfda-document-about-monitoring-vaccine-safety/ (14 May 2021).

10. Ayyadurai, S. R. E. Indictment \& Firing of Anthony Fauci. Shiva4Senate, https://shiva4senate.com/petition-fire-fauci/ (3 April 2020).

11. Olorunnipa, T. et al. Drug promoted by Trump as coronavirus 'game changer' increasingly linked to deaths. The Washington Post, https://www.washingtonpost.com/politics/drug-promoted by-trump-as-coronavirus-game-changer-increasingly-linked-todeaths/2020/05/15/85d024fe-96bd-11ea-9f5e-56d8239bf9ad_ story.html (15 May 2020).

12. Fischer, B. Fauci knew about HCQ in 2005-nobody needed to die. One News Now, https://onenewsnow.com/perspectives/ bryan-fischer/2020/04/27/fauci-knew-about-hcq-in-2005-nobodyneeded-to-die (27 April 2020).

13. Hoft, J. Smoking gun: Fauci lied, millions died - Fauci was informed of hydroxychloroquine success in early 2020 but lied to public instead despite the science \#FauciEmails. Gateway Pundit, https://archive.is/kgwEx\#selection-612.0-612.1 (3 June 2021).

14. Daszak, P. Understanding the risk of bat coronavirus emergence (grant award). NIH Report, https://reporter.nih.gov/search/-bv PCvB7zkyvblAjAgW5Yg/project-details/8674931 (27 May 2014)

15. Douglas, K. M., Sutton, R. M. \& Cichocka, A. Curr. Dir. Psychol. Sci. 26, 538-542 (2017).

16. Kramer, R. \& Gavrieli, D. in Psychology of Leadership (eds Messick, D. \& Kramer, R.) 251-261 (Lawrence Erlbaum Associates, 2005).

17. Lewandowsky, S., Gignac, G. E. \& Oberauer, K. PLoS ONE 8, e75637 (2013).

18. Grimes, D. R. PLoS ONE 16, e0245900 (2021).

19. Retraction Watch. Journal expresses concern - we think about papers by Surgisphere Founder. Retraction Watch, https://retractionwatch.com/2020/12/16/journal-expressesconcern-we-think-about-papers-by-surgisphere-founder/ https://retractionwatch.com/2020/12/16/journal-expressesconcern-we-think-about-papers-by-surgisphere-founder/ (2020).

Competing interests

The author declares no competing interests. 